\title{
Logros y debilidades de la macridiplomacia
}

\author{
Patricio Mateo Carmody ${ }^{1}$
}

La política exterior del presidente Macri procuró redefinir y recalibrar las relaciones internacionales de la Argentina en forma altamente visible. Así, en comparación a otras áreas de gobierno, la acción exterior proporcionó varios momentos de satisfacción. El esfuerzo realizado y el ritmo al que se trabajó fueron encomiables, aunque los logros obtenidos hayan convivido, a veces, con fallas conceptuales y organizacionales que opacaron el impacto de los éxitos diplomáticos. Es en este contexto que mis reflexiones se expresarán en torno a cuatro temas.

\section{La Macridiplomacia: alta visibilidad y momentos de prestigio}

La administración del presidente Macri se esforzó desde un principio y con gran energía en reestablecer y/o redefinir las relaciones internacionales de la Argentina. El presidente ya desde el inicio buscó participar en importantes foros globales como el Foro Económico de Davos, la Cumbre de Seguridad Nuclear en Washington, y la reunión del G20 en Hangzhou (China), procurando reestablecer un relación "normal" con las potencias establecidas, y cultivar vínculos con líderes de las potencias emergentes. En efecto, un aspecto fundamental de este período fue la diplomacia presidencial --la Macridipomacia--, es decir la activa interacción del presidente con líderes mundiales, y su gran esfuerzo personal en promover relaciones y acuerdos, dándole así una alta visibilidad a su política exterior.

Doi: https://doi.org/10.24215/23142766e082

${ }^{1}$ Es Ingeniero Industrial de la Universidad de Buenos Aires, y Master en Administración de Empresas (MBA) del Tuck School of Business, Dartmouth College, en Estados Unidos. Completó el programa de Doctorado en Relaciones Internacionales y Diplomacia de la Ecole de Hautes Etudes Internationales, en París. Complementó estos estudios con programas en la Kennedy School of Goverment, en Harvard, enfocados en comercio, desarrollo y negociaciones internacionales. 
La Macridiplomacia alcanzó momentos de gran prestigio, entre los cuales se destacaron la presidencia del G20 en Buenos Aires en 2018, y la obtención del acuerdo MercosurUnión Europea (UE) en 2019. De este modo la presidencia del G20 en 2018, fue utilizada para reafirmar la voluntad de trabajar con todos los países con interés en cooperar con la Argentina. En esta diplomacia de líderes, creada no para salvar el orden mundial actual, sino que para ir ajustándolo y mejorándolo, se harían sentir las relaciones de poder actuales, por sobre las del pasado.

Macri sería sumamente efectivo en el G20 en su interacción personal con los líderes de potencias establecidas--como Trump, Macron, Merkel y Trudeau--, y de potencias emergentes --como Xi Jingpin y Putin--. Pero también prestaría atención al exterior próximo, invitando a Chile al G20 en Buenos Aires, y presentando en el G20 de 2019 en Osaka, a los presidentes Bolsonaro y Macron. Este encuentro presidencial sería decisivo para la conclusión del acuerdo Mercosur-Unión Europea (UE) que se negociaba en Bruselas.

De este modo, un decidido presidente Macri aprovecharía su rol de líder temporario del Mercosur, su pertenencia a la troika del G-20, y el prestigio ganado por haber organizado con éxito el G-20 en Argentina, para arribar al acuerdo Mercosur-UE, en un contexto complejo, y aprovechando una estrecha ventana de oportunidad.

Es importante resaltar que la Macridiplomacia encarnó un cambio positivo en la manera de tratar a dignatarios y funcionarios extranjeros, dejando de lado la "antidiplomacia" de los gobiernos Kirchner, para adoptar un trato y un tono mesurado y educado. Este ejemplo sería seguido por la Cancillería, que tuvo la ardua tarea de recomponer nuestras relaciones bilaterales con numerosas naciones.

\section{Horizontes diversos: declamaciones y realidades}

En un contexto global donde se verificaba el desplazamiento relativo del poder económico hacia el Asia-Pacífico, era aconsejable para la Argentina adoptar una estrategia de política exterior de "horizontes diversos", o sea el mantener relaciones positivas y simultáneas con las potencias establecidas, las emergentes, y el exterior próximo.

Al analizar la política exterior del gobierno Macri, observamos que su estrategia de "horizontes diversos" fue por momentos más evidente en lo declarativo que en los hechos. Así, la primer canciller Susana Malcorra declaró que "tenemos que maximizar nuestras alternativas y tener una relación seria y madura con todos quellos dispuestos a tabajar con nosotros". Y aunque más tarde, el presidente Macri habló, incluso en el G20 en Buenos Aires, de trabajar con todos los países dispuestos a colaborar, la realidad mostró un gran foco en trabajar con las potencias establecidas, y en particular con EE.UU. Así, se recompusieron estas relaciones, pero sin traducirse lamentablemente en éxitos económico-comerciales en el corto plazo, sino más bien en un substancial endeudamiento con instituciones privadas de ese origen y con el Fondo Monetario Internacional (FMI), generando así una "relación con dependencias". Más aún, expertos de la Universidad Di Tella, como Roberto Russell y Juan Gabriel Tokatlián, observaron un alineamiento injustificado con EE.UU., que se reflejó en la forma de votar en la ONU, o en posiciones con respecto al conflicto Palestino-Israelí. En la misma dirección, tras desactivar el riesgoso eje Caracas-La Habana-Buenos Aires, la Argentina se alineó con EE.UU. en cuanto a Venezuela. Se integró así al Grupo de Lima, que 
reconoció al presidente interino Juan Guaidó e, irónicamente terminaría activando el Tratado Interamericano de Asistencia Recíproca (TIAR) --que los EE.UU. se negaron a activar en Malvinas--, sin existir una amenaza extracontinental. Ni el Perú, cuya capital dió el nombre al Grupo de Lima, votaría por la activación del TIAR.

Sin embargo, en un contexto de conflicto entre EE.UU. y China, la Argentina eludió las presiones domésticas e internacionales para elegir públicamente entre una y otra potencia. Como ejemplo, durante la reunión el G20 en Buenos Aires, y luego de los esfuerzos iniciales del segundo canciller de Macri, Jorge Faurie, en desmentir lo expresado por el equipo del presidente Trump --con respecto a las conductas depredadoras de China--, el presidente lo respaldó. Este agregó además, que a pesar de la opinión de algunos periodistas, no veía a China como una amenaza, sino como una oportunidad, y que había que trabajar con todos los países dispuestos a colaborar.

En efecto, se recalibraron las relaciones con China y Rusia, bajando el tono político de estos vínculos, pero en consecuencia no logrando demasiado en lo económico y en lo tecnológico, más allá de un aumento de un SWAP con China. A su vez, pero sólo en forma tardía, se buscaron profundizar las relaciones con India y la ASEAN, importantes destinos para nuestras exportaciones.

Con respecto al exterior próximo, se recompusieron las relaciones con Chile, luego de haber dejado a ese país sin gas, durante el gobierno Kirchner, y se intensificó la integración económica y física. A su vez, se reencaminaron los vínculos con Uruguay y Paraguay, y se elevaron los horizontes de la relación con Brasil / Mercosur a través de la firma de los tratados con la Unión Europea (UE) y con la EFTA.

\section{Optimismo e inocencia ante la hiperglobalización}

La administración Macri enfrentó su "integración inteligente al mundo" sin cuestionar, y a veces no parecer entender, las reglas de juego de un mundo sumido en un proceso de hiperglobalización. En un entorno global donde, como afirma el profesor de la Universidad de Harvard Dani Rodrik, las economías domésticas parecen estar al servicio de la economía global, en vez de la economía global estar al servicio de las domésticas, las relaciones internacionles se condujeron con un abundante grado de optimismo e inocencia en el campo económico.

Una señal de esto fue la importancia dada a la organización de la Conferencia de Ministros (MC11) de la Organización Mundial de Comercio (OMC). En un momento donde el Secretario General de origen brasileño Roberto Azevêdo no lograba despertar interés para que algún país miembro la realizara --inclusive Brasil--, y donde no parecía haber posibilidades de lograr resultados de importancia, la Argentina se ofreció a organizarla en 2016. La prisa por tener un rol visible en alguno de los "símbolos de participación" en la gobernanza global, primó por sobre un análisis realista de lo que se podía obtener, versus los esfuerzos y recursos a ser utilizados. Los resultados para la Argentina, tanto en lo simbólico como en lo concreto fueron sin duda exiguos, distrayendo la atención de la tarea vital de diseñar una política exterior clara y consistente. Pero también del diseño de una visión de desarrollo, crítica para enfrentar un mundo hiperglobalizado, que para colmo comenzaba a cerrarse, irónicamente, en los aspectos comerciales. 
Otra señal fue la manera de encarar los aspectos financieros a nivel internacional, tanto a nivel de inversiones como de endeudamiento. El proceso de atraer inversiones fue conducido con una combinación de inocencia e impericia. Desde el inicio hizo falta explicar una creíble estrategia de desarrollo y como ésta iba a ser implementada. Esto es normalmente un requisito importante para que los inversores sepan en que contexto económico van a operar, cuáles son los sectores productivos en que deben invertir y en base a que estrategia, como puede ser por ejemplo el construir o potenciar una base productiva para exportar regionalmente. El foco para atraer inversiones se concentró en cambio en la infraestructura y energía, limitando lás áreas de interés, en adición a no describir un horizonte realista y/o atractivo para los otros sectores productivos, más allá de la industria de la tecnología de la información y el sector agroganadero. En consecuencia, la inversión extranjera directa en la Argentina durante estos años fue sumamente exigua.

Con respecto a lo financiero, dos de las grandes falencias de la administración Macri fue la falta de control de los flujos de capital especulativo de corto plazo, y la forma en que se endeudó a nivel internacional. A nivel global, la transición del sistema de Bretton Woods a uno de hiperglobalización, había llevado a que las potencias establecidas liberaran vastas cantidades de financiamiento de corto plazo, para buscar altos retornos más allá de su frontera. Ante esto, era importante no confundir la inversión extranjera directa con inversión especulativa de corto plazo. Era crítico controlar el flujo de capitales de corto plazo para evitar su impacto negativo, dada la escala reducida del mercado interno versus la de los mercados globales. Pero el gobierno de Macri, bajo el ministro Dujovne, tomó el camino contrario, eliminando el control de los capitales especulativos de corto plazo, lo que facilitó la salida repentina y masiva de capitales en diversos momentos, con consecuencias altamente negativas.

En cuanto al endeudamiento, la administración Macri prefirió endeudarse en moneda extranjera para financiar su déficit fiscal, en vez de reducirlo, o procurar una solución que combinara ambos caminos. Así, y aprovechando las favorables condiciones financieras globales, el gobierno fue endeudando a generaciones venideras para cubrir gastos corrientes, en vez de hacerlo para financiar grandes inversiones en infraestructura, que en algún futuro estas generaciones podrían llegar a utilizar. En este proceso, el presidente pareció tomar el camino más fácil, una elección que parece haber sido incentivada por profesionales de las finanzas, tanto locales como internacionales. En este contexto, es relevante recordar la famosa frase de Séneca: "para el que no sabe a que puerto se encamina, no hay viento favorable". Agregando que, si sin saber adonde va, el líder pregunta a alguien cúal viento es el favorable, la respuesta seguramente consistirá en un viento que sea favorable a su interlocutor. El nivel de endeudamiento se convertiría "sorpresiva y repentinamente" en insostenible, obligando al gobierno a buscar un acuerdo con el Fondo Monetario Internacional (FMI). Aquí otra vez, la diplomacia presidencial sería protagonista, logrando el apoyo del presidente Trump para que los cuantiosos préstamos del FMI se materializaran. Lamentablemente este logro presidencial no fue sino la admisión de los errores cometidos, y nos colocaría en una relación "con dependencia" con respecto a los EE.UU. A su vez, la Argentina sería exitosa en extender y aumentar un SWAP con China, logrando así, irónicamente, un nivel de diversificación en su endeudamiento que no pudo lograr en forma significativa ni en las inversiones, ni en las exportaciones.

Las palabras de Séneca se tornan relevantes también al considerar como la administración Macri encaró el proceso de admisión a la Organización de Coperación y Desarrollo 
(OCDE). El trabajo realizado para entrar a este llamado "club de los países ricos", y tener acceso a sus mejores prácticas de gestión económica, fue de un alto nivel profesional, llegándose a ser admitidos en los 23 comités de la organización, que debían aprobar los distintos pasos para la admisión definitiva. También se realizó una valiosa tarea pedagógica sobre estos temas en las clases política y empresaria. Pero lo que faltó durante este proceso fue el tener una clara visión de desarrollo, que ayudara a analizar la conveniencia de incorporar y priorizar cada una de las recomendaciones formuladas por la OCDE, determinando cuales de éstas serían verdaderos "vientos favorables", en el mediano y largo plazo.

Otro signo de alerta fue la falta de profundidad, y a veces de la relevancia de los mensajes del presidente, al hablar en escenarios internacionales. Un ejemplo de esto fue un discurso pronunciado en la Fundación Konrad Adenauer, en su visita a Berlín en 2016. Enfrente de importantes políticos y académicos, describió a su política exterior como una basada en alcanzar tres objetivos: pobreza cero, lucha contra el narcotráfico, unidad de los argentinos. Si bien estos pudieron haber sido un importante slogan de campaña, definitivamente no eran las bases de una política exterior. En esta, como en otras ocasiones, se podía apreciar una cierta inocencia de parte del presidente, y un apreciable desconocimiento de como razonan los políticos, académicos y empresarios extranjeros --en el ejemplo citado, los alemanes-- por parte de sus asesores en política exterior.

\section{Una limitada contribución al desarrollo}

La Macridiplomacia tuvo, como vimos, altos niveles de dinamismo, visibilidad y protagonismo, con momentos de gran prestigio. Sin embargo, siendo la Argentina una potencia media en lo económico, y que se encuentra ubicada en una "zona de paz", es fundamental que la política exterior contribuya a su desarrollo. En este contexto, si bien la política exterior fue muy efectiva en cuanto a lo que podemos denominar las "relaciones públicas internacionales", los resultados concretos en cuanto a la contribución al desarrollo, no fueron proporcionales a los éxitos diplomáticos alcanzados.

Varias imperfeciones en el diseño de la estructura de la política exterior influyeron para que esto ocurra. La primera fue la organización de un esquema de diplomacia supraministerial, donde el Secretario de Asuntos Estratégicos --Fulvio Pompeo--que reportaba al Jefe de Gabinete Marcos Peña, controlaba directamente a la Cancillería. Pero a esto se sumaba la particular visión de Pompeo, quien buscaba enfocarse en temas de política exterior y Defensa, siéndole indiferente desde un principio la temática del comercio exterior. De este modo para Pompeo era lo mismo si el comercio exterior dependía de la Cancillería o del Ministerio de Producción, una disputa que se planteó en el tiempo de Susana Malcorra, la primera canciller de la administración Macri.

La estructura de Diplomacia Supraministerial claramente limitó el prestigio y los grados de acción de la Cancillería y su impacto en cuanto a su contribucón al desarrollo. En efecto, el canciller de convirtió en el cuarto nivel de mando de la política exterior, después del Presidente, el Jefe de Gabinete, y el Secretario de Asuntos Estratégicos. Esto podía verse simbólicamente en la posición que ocupaban estos funcionarios en las reuniones del plenario del G20.

Irónicamente, ni la Cancillería ni el Ministerio de Producción tuvieron una influencia significativa sobre las decisiones económicas que impactaron el comercio exterior. Medidas 
como las implementadas exitosamente por el exministro chileno Hernán Büchi --mantener un tipo de cambio real alto, no exportar impuestos, impulsar la promoción comercial--, no tuvieron defensores de peso dentro del Gabinete. Tampoco existió una firme resistencia a la suba de retenciones a las exportaciones generalizada que implementó el ministro Dujovne, dando la sensación de que lo financiero, aunque mal manejado, siempre primó sobre lo productivo y sobre las exportaciones, en el equipo gubernamental.

Concluyendo, las relaciones internacionales de la administración Macri proporcionaron varios momentos positivos y memorables. Pero a pesar del ritmo y entusiasmo con el que se trabajó, algunas fallas conceptuales, de organización y de estructura, hicieron que los resultados concretos obtenidos no hayan sido proporcionales a los kilómetros viajados, y a los recursos invertidos. 